\title{
novers

\section{O papel exercido pela mulher no comércio do centro de Tubarão}

\author{
Jéssica Damas de Souza' \\ Jéssica Lippert Policarpo ${ }^{2}$ \\ Thiago Paes Marcelo ${ }^{3}$ \\ Vitor Vieira Nandi ${ }^{4}$ \\ Cláudia Nandi Formentin ${ }^{5}$ \\ Marília Köenig ${ }^{6}$
}

\section{RESUMO}

O presente artigo destaca os resultados parciais obtidos no Projeto de Iniciação Científica - PIC Senac da Faculdade de Tecnologia Senac Tubarão em 2011, o qual investiga o papel exercido pela mulher no comércio de rua do centro de Tubarão. Para tanto, far-se-á um retrospecto da evolução da atuação feminina em sociedade, sobretudo, no mundo corporativo. Em seguida, será exposta a metodologia do trabalho, bem como os resultados parciais alcançados. No que diz respeito à metodologia, este artigo apoia-se, inicialmente, em pesquisa bibliográfica e, posteriormente, na pesquisa. A primeira parte envolveu a aplicação de questionário junto a um contingente de gestores do universo de pesquisa proposto. Percebeu-se, neste contingente (parte do grupo de gestores entrevistados), que os homens têm prevalência na gestão dos estabelecimentos comerciais, embora seja crescente a participação da mulher no comando dessas organizações.

Palavras-chave: Gênero. Mulher. Comércio. Gestão de pessoas

\section{INTRODUÇÃO}

O presente artigo é parte integrante do PIC Senac da Faculdade de Tecnologia Senac Tubarão, no qual se pretende investigar a seguinte questão: que papéis a mulher ocupa no comércio de rua do centro de Tubarão? Para tanto, se traçará um breve panorama da condição feminina, sua inserção no mercado de trabalho e os consequentes desafios em que essa questão implica.

O objetivo geral do trabalho ora exposto é investigar quais as posições ocupadas pela mulher no comércio do centro de Tubarão. Quanto aos objetivos específicos, têm-se os seguintes.

- Traçar um perfil das mulheres que atuam no comércio de Tubarão.

1 Aluna bolsista do Programa de Iniciação Científica da Faculdade Senac - Tubarão e acadêmica do quartosemestre do curso de Tecnologia em Gestão de Recursos Humanos. 2 Alunabolsista do Programa de Iniciação Científica da Faculdade Senac - Tubarão e acadêmica do segundo semestre do curso de Tecnologiaem Gestão de Recursos Humanos. 3 Aluno bolsista do Programade Iniciação Científica da Faculdade Senac - Tubarão e acadêmico do segundo semestre do curso de Tecnologia em Processos Gerenciais. 4 Aluno bolsista do Programa de Iniciação Científica da Faculdade Senac - Tubarão e acadêmico dosegundosemestre do curso de Tecnologiaem Gestão de Recursos Humanos. 5 Professorana Faculdade de Tecnologia Senac Tubarão

6 Professora coordenadora do Programa de Iniciação Científica da Faculdade Senac Tubarão. Bacharel em Jornalismo, especialista em Comunicação nas Organizações, mestre em Ciências da Linguagem, todos já concluídos na Universidade do Sul de Santa Catarina (Unisul) e doutoranda do Programa de Pós-Graduação em Ciências da Linguagem, realizadona instituiçãojá citada. Além de professora na Faculdade Satc, também trabalha como docentena Faculdade Satc (Criciúma). 
- Pesquisar a média salarial destas mulheres.

- Buscar conhecer os motivos pelos quais os gestores optam pela contratação de mulheres;

- Identificar as razões pelas quais as mulheres buscam empregar-se nos estabelecimentos comerciais.

Cabe salientar que o projeto ainda está em andamento, portanto, este artigo tem, evidentemente, um objetivo menor que o do trabalho. 0 intuito do presente artigo é investigar, a partir de referencial bibliográfico e pelos resultados parciais já alcançados, quais espaços a mulher vem tomando no mercado de trabalho e, a partir das entrevistas com os gestores, identificar quais as posições ocupadas pelas mulheres no comércio da cidade de Tubarão, Santa Catarina.

As hipóteses que motivaram a elaboração do projeto e, consequentemente, a produção do presente artigo foram:

a) As mulheres do comércio de rua do centro de Tubarão são, em sua maioria, parte da linha de frente (vendas), porque as características culturalmente atribuídas a elas (atenção, visão sistêmica, organização, carisma, sensibilidade, empatia, e etc.) fazem com se destaquem nesta área.

b) Em contrapartida, não obstante a essas qualidades, elas ocupam, menos frequentemente que os homens, posição de gestão/liderança no universo pesquisado.

\section{ATRAJETÓRIA FEMININA AO LONGODOTEMPO}

A maioria dos mamíferos centra suas relações na dupla mãe/filho. Formam, portanto, 'comunidades' matricêntricas. Segundo Seixas $(1998$, p. 26) "a dominância da fêmea não se traduz em dominação, já que não pratica a coerção da vontade dos outros membros do grupo". Na pré-história os proto-humanos e também os primatas possuem esta característica embora, "segundo a interpretação corrente, os bandos de animais se reúnam em torno de um macho dominante que escraviza os outros e se apodera das fêmeas" (SEIXAS, 1998, p. 26).

Os hominídeos, durante o período Paleolítico, iniciaram a caça e tornaram-se, por conta disso, carnívoros. É deste processo que surge a divisão de trabalho mais antiga da história. 0 homem torna-se caçador e a mulher colhedora. Provavelmente esta divisão se dá com base nas diferenças biológicas entre homem e mulher. "Como a mulher passa a maior parte do tempo grávida ou amamentando, é a ela que cabe alimentar os filhotes. Mas, como não pode esperar indefinidamente pelo produto incerto da caçada, aprende a cultivar a terra e cria o espaço doméstico" (ARATANGY apud SEIXAS, 1998, p. 27).

No Egito antigo, a cultura ainda segue matricêntrica. "Homens e mulheres têm os mesmos direitos e, na maioria das vezes, o poder é exercido pelas mulheres dos faraós" (SEIXAS, 1998, p. 31). Na Grécia antiga, as características de cada cidade-estado definem a função feminina na sociedade.

Em Atenas, as mulheres não têm os mesmos direitos políticos e legais do que os escravos e não recebem educação formal. (...) Já em Esparta, as mulheres possuem maior autonomia, embora continuem sem direitos políticos e sejam consideradas inferiores aos homens. A autonomia feminina tem origem na infância, quando meninas e meninos são educados conjuntamente em atividades guerreiras. Além disso, os homens ficam afastados de casa por longo tempo, em manobras militares, facilitando essa autonomia (SEIXAS, 1998, p. 31).

A sociedade romana é patriarcal. Os chefes de família têm todos os direitos sobre os membros dos clãs. A falta de reconhecimento chega ao ponto da mulher não ter um nome próprio e recebêlo do pai.

Segundo Seixas (1998), durante a Idade Média, o Cristianismo patriarcal define a 
mulher/esposa como fraca, frágil, lenta no entendimento, emocionalmente instável e uma ameaça sexual. 0 cristianismo, na afirmação do autor, é bastante severo para com a mulher. "A mulher e o prazer são instrumentos do diabo", coloca Seixas (1998, p. 48). Apesar destas informações, Perrot (apud NOGUEIRA, 2004) afirma que a Idade Média é um período em que a história pouco registra a condição feminina.

Durante a Idade Moderna, especificamente durante o século XVI, a educação intelectual e artística passa a estar ao alcance das mulheres, que começam a se tornar mais atraentes. Nesse período da história da humanidade surgem mulheres que ganham destaque na sociedade, mas o sistema educacional implantado no Brasil, em 1549, pelos jesuítas, dedica-se ao ensino de meninos.

Na cultura brasileira, assim como na maior parte da cultura ocidental, isso fica claro quando Seixas (1998, p. 67) afirma que "o chefe de família cuida dos negócios, preserva a linhagem e a honra familiar, exerce a autoridade sobre a mulher, filhos e dependentes". Já a mulher, afirma a autora, é quem "cuida dos filhos e da casa, fica restrita ao lar e tem poucas oportunidades de aparecer em público" (SEIXAS, 1998, p. 67). Histórica e culturalmente, dentro da sociedade ocidental, o papel da mulher está centrado na casa e na família. Na vida privada, por assim dizer.

No período contemporâneo, a ideia da mulher, exclusivamente em casa, vai mudando aos poucos. À medida que o capitalismo vai se desenvolvendo, passa a haver a necessidade de uma maior renda familiar para a sobrevivência deste núcleo. A mulher entra nesse momento para contribuir e ajudar com esta renda, a qual não é a renda principal.

A moda também acompanha essa entrada nas fábricas: saem as saias volumosas e entram as roupas mais comedidas. A condição desigual da mulher nesse período, já entrando no século XX, serve de mote à movimentos que mudarão parte da estrutura social. Em todas as sociedades, em vários períodos temporais, especialmente no período agora citado, "a mulher desempenha, simultaneamente, vários papéis: ela é mãe, esposa, dona de casa, conselheira e, em muitos casos, a provedora do sustento familiar" (CONFORTIN, 2003, p. 107).

Tão antiga quanto essa quantidade significativa de tarefas, afirma ainda a autora, "estão a desvalorização dos papéis desempenhados e a da própria mulher" (CONFORTIN, 2003, p. 107).

Nos anos de 1970 um novo processo de conscientização feminina começa a aparecer, especialmente no que diz respeito às lutas que se referem à emancipação feminina. Segundo Nogueira (2004, p. 37),

nessa época, a mulher trabalhadora acentuava a sua participação nas lutas de sua classe e na organização política e sindical. Mantinha-se o enfrentamento em relação ao discurso conservador que preconizava um destino natural para a mulher: ser mãe e esposa, mantendo o conceito de família como instituição básica e universal.

Nesse momento, reforça a autora, era necessário combater de fato, a opressão contra a mulher. Segundo ela, era preciso

\begin{abstract}
lutar pela emancipação econômica e social, pelo direito ao trabalho, com todas as especificidades que isso implica, como, por exemplo, salários iguais para trabalhos iguais, além da reivindicação de uma divisão mais justa no trabalho doméstico, na esfera reprodutiva, libertando, ao menos parcialmente, a mulher da dupla jornada (NOGUEIRA, 2004, p.37).
\end{abstract}

\title{
2.1 Discussões de gênero
}

Gênero (termo que advém do inglês gender) foi uma categoria introduzida no final dos anos 80 do século passado, em especial, por intermédio das feministas anglo-saxãs, como uma evolução das discussões anteriores que giravam em torno da diferença entre homens e mulheres e os princípios masculinos e femininos, passando, no entanto, longe das questões inerentes ao poder atribuído ao homem (MURARO; BOFF, 2010). 
As discussões de gênero são tão antigas quanto à humanidade. Nas palavras de Muraro e Boff (2010, p. 16), "ambas as categorias atravessam as sociedades históricas, trazem à luz os conflitos entre homens e mulheres e definem forma de representar a realidade social e intervir nela".

Serviram também, de acordo com os autores, para segregar homens e mulheres, o que, historicamente, tem contribuído para a crise que ora a humanidade atravessa.

Atividade e agressividade versus passividade e acolhimento, lembram os autores, "são características tradicionais de ambos os gêneros, que, atualmente, começam a passar por transformações rápidas" (MURARO; BOFF, 2010, p. 17).

Guizelini (2011), no artigo "A mulher no comando do mundo corporativo" mostra que os estudos dos movimentos feministas buscavam alcançar direitos iguais e o desejo da mulher de se inserir no mercado de trabalho, não só em posições de menor representação, mas também ter a oportunidade de participar de cargos ocupados pelos homens. E é justamente essa questão que o trabalho ora formulado alude ao investigar a posição ocupada pelas mulheres no comércio do centro do município de Tubarão.

Contudo, não obstante à crise que o sistema patriarcal vive, contemporaneamente, o mundo ainda está mergulhado nele, por meio das instituições e da lei. 0 mundo, pode-se afirmar, ainda "pensa" e se estrutura sobre a égide masculina em que a figura do varão ainda é central, há quatro milanos.

\subsection{A mulher no mundo corporativo}

Com a consolidação do sistema capitalista no século XIX, algumas leis passaram a beneficiar as mulheres, que começaram, de forma mais ostensiva, uma luta organizada em defesa de seus direitos. A partir dessa data é que começam a acontecer as primeiras revoluções do chamado sexo frágil, juntamente com as grandes revoluções desse século.

Assim, as mulheres começaram a ganhar seu espaço. A luta delas contra as formas de opressão a que eram submetidas foi denominada de feminismo e a organização das mulheres, em prol de melhorias na infraestrutura social, foi conhecida como movimento de mulheres.

O movimento feminista, sobretudo, nas décadas de 1960, 70 e 80, conquistou a palavra e desempenhou um papel fundamental, inscrevendo o feminino como uma categoria essencial para uma política de identificação cultural. Mas, conforme destacado anteriormente, começou quase um século antes, quando as mulheres ocupavam de forma definitiva os espaços nas ruas, no trabalho, nas escolas, nas universidades e na política.

As mulheres que assumiram o movimento feminista foram vistas como "mal amadas" e discriminadas pelos homens, e também pelas mulheres que aceitavam o seu papel submisso na sociedade patriarcal.

A partir das duas grandes Guerras Mundiais (1914-1918 e 1939-1945), as mulheres passaram a ocupar os lugares dos homens que se ausentavam para lutar nos conflitos. Depois do término das batalhas, quando tudo voltou ao normal, as mulheres não se conformaram em ter de voltar à rotina em prol da casa e do marido. Naquele tempo, em geral, as mulheres que trabalhavam ou eram viúvas ou não eram casadas e tinham filhos para criar. Elas trabalhavam fazendo doces, costurando, ensinando a tocar piano e ganhavam pouquíssimo com suas atividades.

Com a Revolução Industrial, aumentava consideravelmente o número de mulheres empregadas. Elas passaram a trabalhar com os maquinários, pois a demanda de mão de obra aumentava cada vez mais. Junto com a oportunidade de trabalhar, veio a exploração. As trabalhadoras tinham jornadas de trabalho de 14 e 18 horas diárias e seus salários eram irrisórios. Neste contexto, apesar de serem altamente exploradas e receberem salários muito inferiores aos dos homens, o trabalho permitiu às mulheres uma independência econômica que antes não tinham. 
Com o passar do tempo, portanto, a mulher foi ocupando cargos e lutando por melhorias de salários, redução na jornada de trabalho, licença-maternidade, direito de voto. Conquistou, ainda, o acesso às profissões de nível superior (como Medicina, Advocacia, Engenharia, entre outras).

Nesse cenário, segundo Costa (1994, p. 161), "os gêneros passam a ser entendidos como processos também moldados por escolhas individuais e por pressões situacionais compreensíveis somente no contexto da interação social".

Com base nos dados da Relação Anual de Informações Sociais (RAIS) e Cadastro Geral de Empregados e Desempregados (CAGED), segundo o Sistema Nacional de Emprego (2011), as mulheres estão mais presentes nos grupos com maior perfil de escolaridade. Aproximadamente $58 \%$ do conjunto dos postos de trabalho formais já são ocupados por trabalhadores que completaram, pelo menos, o ensino médio. Entre as mulheres esta proporção atinge 64\%, e entre os homens, apenas 53\%, conforme a mesma pesquisa.

Percebeu-se, ainda por intermédio dessa pesquisa, que as meninas vão melhor na escola, inclusive, em matemática, uma matéria na qual os homens supostamente têm uma vantagem imediata. 0 que ainda sustenta os homens é seu comportamento mais agressivo e competitivo.

Entre homens e mulheres com nível superior completo da População Economicamente Ativa (PEA), os números delas ultrapassaram os deles. As mulheres atingiram 53,6\%, enquanto os homens, em 2010 , tinham $51,3 \%$. No Brasil, $55 \%$ das pessoas que entram na faculdade e $59 \%$ das que terminam, são mulheres. Seja porque eles começam a trabalhar mais cedo, seja por falta de interesse, 40\% dos homens largam estudos em todos os níveis. Entre os países desenvolvidos, os Estados Unidos (EUA) tem um dos menores índices de mulheres de nível universitário no mercado de trabalho. Apenas na Turquia, Irlanda, Suíça e Holanda uma proporção menor de graduadas trabalha por salários. Nos EUA, já estão aceitando até a possibilidade de cotas para homens em universidades.

Embora 97\% dos CEOs (chefes executivos) ainda sejam homens, elas já ocupam cerca de 40\% dos cargos de gerência. 0 emprego feminino cresceu em uma velocidade ainda maior que o emprego masculino, alcançando uma taxa média anual de 5,1\% contra 3,2\% do emprego masculino (período de 1985 a 2010). Contudo, à medida que as mulheres sobem a escada corporativa, têm cada vez menos tempo de criar e manter relacionamentos. As mulheres trabalham, e ainda são responsáveis por $90 \%$ do cuidado com os filhos e das tarefas domésticas.

A RAIS identifica ainda, que na média estadual, as mulheres foram contratadas recebendo, mensalmente, $15,3 \%$ a menos que os homens. 0 diferencial entre a remuneração feminina e masculina é semelhante em todos os aglomerados geográficos (SISTEMA NACIONAL DE EMPREGO, 2011).

Segundo Hueck (2011, p. 53)

\begin{abstract}
um estudo realizado pela fundação americana Gallop, em 2003, perguntou que carreiras eram as mais desejadas entre os adolescentes. Para os garotos, profissões relacionadas à Computação estavam em primeiro lugar, seguidas das engenharias. Elas, por sua vez, disseram querer Artes Cênicas, Música e Educação. E eis o problema: Computação e Engenharia são as áreas que pagarão os melhores salários nos próximos anos.
\end{abstract}

Os diferenciais no modo de inserção no mercado de trabalho entre os gêneros parecem explicar a diferença salarial entre homens e mulheres, especialmente quando ambos têm formação superior completa.

Ainda com base em Hueck (2011, p. 55),

percebe-se em pesquisas, que as mulheres quando são gananciosas e passam a subir de cargo no âmbito de trabalho, as pessoas deixam de gostar delas. Pois basta que essas se tornem chefes para que as pessoas a sua volta comecem a vê-la com desconfiança. Para com o homem, isso é menos comum, pois o fato de ser bem-sucedido o torna admirável. 
Vale lembrar que a remuneração média feminina é inferior à masculina em todos os níveis de escolaridade, sendo verificadas as maiores diferenças nos graus de instrução superior incompleto e superior completo.

Apesar de tantas dificuldades, as mulheres conquistaram um espaço de respeito na sociedade. Hoje, é comum ouvir em conversas informais: "os tempos mudaram; homens e mulheres nos dias de hoje já têm os mesmos direitos"; "as mulheres fazem o que querem", ou frases parecidas que tornam definitivas e terminadas as conquistas das mulheres, estabelecendo como patamar de igualdade de gênero, o quadro atual da condição das mulheres na nossa sociedade.

\subsection{Mudanças expressivas}

Não se pode esquecer que tanto mulheres quanto homens exercem inúmeros papéis em sua vida cotidiana. Participam da dinâmica social das mais diversas formas. "As mulheres têm uma abordagem mais colaborativa do que a dos homens. Infelizmente, essa estratégia costuma ser mal interpretada e dá a elas um ar de fraqueza porque elas não pedem o que querem e ficam quietas", diz Babcock (apud HUECK, 2011, p.55).

Nos últimos dez anos, a proporção de mulheres líderes de família aumentou em $81 \%$. Pelos dados mencionados, vê-se que são elas que sustentam ou possuem a maior parte do orçamento familiar. Isso mostra como a mulher exerce um significativo papel, tanto na família como na sociedade, pois ela trabalha, sustenta a casa e, muitas vezes, estuda durante a noite.

As pesquisas também demonstram que, ao contrário do que pensa o senso comum, a razão não é um privilégio masculino. As mulheres estão se tornando favoritas pela criatividade e pelo bom relacionamento com os colaboradores, e tem mais, a intuição da mulher está sendo bem aceita dentro das empresas. Esse feeling, aliado à versatilidade de tomar decisões está sendo muito procurado pelas empresas, sendo a característica mais marcante das mulheres.

A crescente entrada da mulher no mercado de trabalho, nas últimas décadas, é chamada, segundo Nogueira (2004, p. 67), de "feminização do trabalho". Mas não obstante à multiplicidade de papéis desempenhados pela mulher, desvalorizam-se esses papéis e a mulher como sujeito ao longo do tempo, conforme destaca Confortin (2003, p. 107). A autora reitera que ela (a mulher) "continuou sendo vista como um ser inferior, incapaz de exercer plenamente sua cidadania [...] e a ser discriminada por suas habilidades profissionais, por salários abaixo dos pagos a homens em igual função".

Com base nessa premissa, fundamenta-se a hipótese central deste trabalho. Embora a mulher, por suas qualidades (biológicas ou culturais, conforme as teorias que falam das diferenças de gênero (MURARO; BOFF, 2010) a destaquem na atividade comercial, é muito mais frequente encontrá-la nas funções operacionais (na linha de frente, no caixa ou nas vendas) e não na gestão de um estabelecimento, por exemplo.

\section{PROCEDIMENTOS METODOLÓGICOS}

A primeira etapa de toda pesquisa científica é o desenvolvimento de uma pesquisa bibliográfica e, se necessário, documental apurada. Este será também o primeiro passo a ser dado neste trabalho.

Para o desenvolvimento desta pesquisa, acredita-se que a melhor alternativa é a aplicação de questionários aos gestores e às colaboradoras. Estes questionários serão compostos, inicialmente, por perguntas objetivas que possibilitarão alcançar os objetivos propostos por este trabalho. Para tanto, serão aplicados entre os gestores e as colaboradoras. Neste sentido, buscarse-á atribuir números às perguntas propostas. Tal técnica caracteriza a abordagem quantitativa. 
Entende-se que o projeto aqui proposto tem como estratégia, a pesquisa diagnóstico. Isso porque esta se "propõe explorar o ambiente, levantando e definindo problemas" (MARTINS; THEÓPHILO, 2009, p. 80). Estudar a mulher no ambiente profissional e tentar, de alguma forma, diagnosticar a situação desta. Desse modo, procura-se avaliar questões ligadas à motivação e à satisfação deste público dentro das organizações pesquisadas.

\section{RESULTADOS PRELIMINARES}

Foram seguidos todos os passos conforme havia sido planejado no cronograma. Foram realizadas leituras, pesquisas, debates, ensaios, entrevistas com gestores, apresentação de resultados e metas alcançadas.

Percebeu-se que as mulheres estão na linha de frente no comércio de Tubarão. Pôde-se vislumbrar essa preferência, haja vista, no entendimento dos gestores pesquisados, pelo fato delas serem mais organizadas, carismáticas, atenciosas e empáticas.

Em contrapartida, elas ocupam em menor número, cargos na área de gestão ou até mesmo, liderança. Dos gestores dos 30 estabelecimentos pesquisados até o momento, por meio de questionário aplicado aos proprietários e gerentes das lojas localizadas na faixa pesquisada, apenas dois eram mulheres.

Conforme a pesquisa realizada e os dados coletados pelo questionário até o presente momento, pôde-se perceber que o perfil do gestor atual no comércio de Tubarão é marcado pelas seguintes características:

a) No cargo de gestor predominam homens, havendo uma proporção de 1 mulher para cada 6 homens.

b) Todos os gestores entrevistados eram sócios-proprietários e estão na faixa economicamente ativa, pois a faixa etária média está entre 20 e 39 anos.

c) Dentre os estabelecimentos, os segmentos que mais se destacam na comercialização são: calçados e acessórios, roupas masculinas e/ou femininas.

Segundo os gestores entrevistados, quem mais procura as oportunidades de emprego em seus respectivos estabelecimentos são as mulheres (70\% das respostas) entre 18 a 25 anos, o que parece indicar que o comércio é uma opção para o primeiro emprego em Tubarão. Em menor proporção, procuram as oportunidades, mulheres na faixa etária entre 25 a 35 anos e, consequentemente, são as mais contratadas.

Em relação à faixa etária dos funcionários, foram feitas as observações a seguir.

"Pela identificação com o público jovem que é grande consumidor de nossos produtos".

"Não procuro faixa etária e, sim, pessoas que realmente querem trabalhar".

"(Deve haver) disposição para os desafios diários".

"Trabalho com roupas femininas e a marca corresponde a essa faixa etária”.

"(Deve haver) experiência e vontade de crescer".

Voltando à participação das mulheres no comércio, estas estão mais presentes na área de vendas, conforme indicam $71 \%$ das respostas obtidas pelo questionário, com uma minoria no setor financeiro, apenas 16,6\%. Há predominância da escolaridade (Ensino Médio completo). Algumas organizações entrevistadas possuem colaboradores com nível fundamental completo e/ ou incompleto.

A rotatividade nos estabelecimentos pesquisados foi classificada como média, ou seja, ocorrem alterações no quadro de funcionários no período semestral à anual. 0 treinamento mais utilizado pelas empresas são cursos de vendas e/ou palestras motivacionais oferecidas para os seus colaboradores.

Utilizando a parte de divulgação de emprego, as empresas adotam os métodos de: Anúncios (TV, rádio, internet), dentre outras técnicas de recrutamento. Já na parte da escolha dos 
profissionais, os métodos utilizados nas empresas são os que seguem:

- Entrevista;

- Experiência;

- Por meio de empresas especializadas;

- Competência (mediante trabalho).

As características desejáveis pelos gestores, com relação aos colaboradores são:

- Atenção com os clientes;

- Facilidade na comunicação interpessoal;

- Articulação;

- Boa aparência;

- Simpatia;

- Atitude;

- Entender a necessidade do cliente;

- Demonstrar interesse em conhecer o produto que esteja vendendo.

$\mathrm{Na}$ etapa de seleção, as empresas visam mais funcionários jovens do que aqueles com experiência. Acredita-se que jovens não entrem exigindo um salário igual ao de uma pessoa com experiência, e também, são vistos como pessoas mais flexíveis, que têm vontade de trabalhar.

Com relação à moradia dos colaboradores para com acesso ao seu local de trabalho, há um equilíbrio entre esses que moram perto ou longe do local de trabalho.

Já no quesito de abordagens aos seus clientes, os gestores procuram que os seus colaboradores não comentem erros como:

- Distinguir o cliente pela aparência;

- Deixar o cliente esperando para atender outro; e

- Forçar a venda de um produto fazendo falsos elogios (dizer que "ficou lindo" quando não ficou, por exemplo).

É com base nessas informações que se pode ter uma noção básica da influência da mulher no mercado de trabalho, em especial, no comércio. Na próxima etapa, serão entrevistados os demais gestores e as colaboradoras da parte do comércio de rua do município de Tubarão, que está sendo pesquisado visando à corroboração ou refutação das hipóteses traçadas no início do projeto de pesquisa aqui referido. Como conclusão (ou uma consideração final no que tange à primeira etapa do trabalho), pode-se destacar a participação crescente da mulher no comércio. Embora no contingente de gestores pesquisado se tenha uma mulher para cada seis homens, denota-se uma evolução.

\section{CONSIDERAÇÕES FINAIS}

Com base nos dados pesquisados até o presente momento, foi possível perceber que as características femininas presentes no imaginário coletivo ao longo do tempo estão presentes nos discursos apresentados pelos gestores entrevistados. Neles, a mulher aparece como sendo organizada, carismática e atenciosa.

A construção deste artigo, baseada na pesquisa em andamento, possibilitou identificar questões, que parecem ainda ser, causadoras de conflito na sociedade. As características apresentadas pelos gestores, por exemplo, são positivas, mesmo que não pareçam credenciar a mulher para cargos de gestão. Será que se a candidata não parecer carismática e atenciosa ela terá chance de ser gestora? Ou será que se isso acontecer, dirão que ela não tem habilidades para os cargos que envolvem a área comercial?

Estas são perguntas que, sem dúvida, ainda merecem certa atenção, pois são nos discursos que envolvem as possíveis respostas dadas que estarão presentes as marcas de uma sociedade que ainda vela os diversos preconceitos e a perpetuação de uma série de estereótipos. 
Na cidade de Tubarão, compreender estas relações de gênero dentro do comércio se faz fundamental para os alunos dos cursos de Tecnologia em Processos Gerenciais e em Gestão de Recursos Humanos, já que é este o setor econômico preponderante no município.

Concluiu-se este artigo, porém, com ele, surgiram tantas outras perguntas não feitas no início do trabalho de pesquisa. Isso nos indica que nesta próxima parte deveremos nos preocupar ainda mais e que há um campo de trabalho grande para esta área.

\section{THE PARTICIPATION OF WOMEN IN BUSINESS IN THE DOWNTOWN AREA OF TUBARÃO}

\section{ABSTRACT}

This article presents partial results obtained in Projeto de Iniciação Científica da Faculdade SENAC - Tubarão, 2011. It investigates the role exercised by women in high street trading in the downtown area of Tubarão (SC). For this purpose, we carried out a retrospective study of the role played by women in the evolution of society mainly in the business world. Next, we exposed the methodology applied for the article which was based in references and in the partial results achieved. This first part involved the application of a questionnaire to a sample of managers. As a result we observed, that among the group of managers interviewed, men prevail in managing positions of commercial establishments, although the number of women in a leading roles in these organizations is increasing.

Keywords: Gender. Woman. Commerce.

\section{REFERÊNCIAS}

CONFORTIN, Helena. Discurso e Gênero: a mulher em foco. In: GHILARDI-LUCENA, Maria Inês (org.). Representações do Feminino. Campinas: Átomo, 2003. p.107 - 123.

COSTA, Lúcia Cortes da. Gênero: Uma Questão Feminina? [1994]. Disponível em:

<http://www.uepg.br/nupes/genero.htm>. Acesso em: 20 jul. 2011.

GUIZELINI, Marta Cristina. A mulher no comando do mundo corporativo. [2011]. Disponível em <http://www.artigocientifico.tebas.kinghost.net>. Acesso em: 09 maio 2011.

HUECK, Karin. Homens x mulheres: por que eles estão ficando para trás. Superinteressante, Rio de Janeiro, n. 292, p.48-p. 57, jun./ 2011

MARTINS, Gilberto de Andrade; THEÓPHILO, Carlos Renato. Metodologia da Investigação Científica para Ciências Sociais Aplicadas. 2. ed. São Paulo: Atlas, 2009.

MURARO, Rose Marie; BOFF, Leonardo. Feminino e masculino: uma nova consciência para o encontro das diferenças. Rio de Janeiro: Record, 2010.

NOGUEIRA, Claudia Mazzei. A feminização no mundo do trabalho: entre a emancipação e a precarização. Campinas: Autores associados, 2004.

SEIXAS, Ana Maria Ramos. Sexualidade Feminina: história, cultura, família - personalidade \& psicodrama. São Paulo: Senac São Paulo, 1998.

SISTEMA NACIONAL DE EMPREGO. A Mulher no Mercado de Trabalho Formal em Santa Catarina. [2011].

Disponível em: <http://www.sine.sc.gov.br/index.php?page=noticias/not_leia_mais.php\&cod=21> Acesso em: 16 jun. 2011. 